\title{
Induction of apoptosis by pectenotoxin-2 is mediated with the induction of DR4/DR5, Egr-1 and NAG-1, activation of caspases and modulation of the Bcl-2 family in p53-deficient Hep3B hepatocellular carcinoma cells
}

\author{
DONG YEOK SHIN ${ }^{1,2}$, GI YOUNG KIM ${ }^{3}$, NAM DEUK KIM ${ }^{4}$, JEE HYUNG JUNG ${ }^{4}$, \\ SE-KWON KIM ${ }^{5}$, HO SUNG KANG ${ }^{2}$ and YUNG HYUN CHOI ${ }^{1,6}$
}

\begin{abstract}
${ }^{1}$ Department of Biochemistry, Dongeui University College of Oriental Medicine, Busan 614-052; ${ }^{2}$ Department of Molecular Biology, Pusan National University, Busan 609-735; ${ }^{3}$ Faculty of Applied Marine Science, Cheju National University, Jeju 690-756; ${ }^{4}$ Department of Pharmacy and Pusan Cancer Research Center, Pusan National University, Busan 609-735; ${ }^{5}$ Department of Chemistry and Marine Bioprocess Research Center, Pukyong National University, Busan 608-737;

${ }^{6}$ Department of Biomaterial Control (BK21 program), Dongeui University Graduate School, Busan 614-052, Korea
\end{abstract}

Received September 27, 2007; Accepted November 21, 2007

\begin{abstract}
The tumor suppressor protein p53 restricts proliferation in response to DNA damage or the deregulation of mitogenic oncogenes, by leading to the induction of various cell cycle checkpoints, apoptosis or cellular senescence. Consequently, p53 mutations increase cell proliferation and survival and in some settings promote genomic instability and resistance to certain anti-cancer drugs. It is very important to identify chemotherapeutic agents that activate in a p53-independent manner for the development of treatments for p53-deficient tumors. Pectenotoxin-2 (PTX-2), isolated from marine sponges has been reported to display significant cytotoxicity to p53-deficient cancer cell lines. In this study, we compared the anti-cancer activity of PTX-2 in order to further test the status of p53 using two well-known hepatocarcinoma cell lines, p53-deficient Hep3B and p53wild-type HepG2. MTT assay indicated that Hep3B cells were highly susceptible, whereas HepG2 cells were more resistant to this compound which was connected with the induction of apoptotic cell death in p53-deficient Hep3B cells, though not in HepG2 cells. The apoptosis induced by PTX-2 in Hep3B cells was associated with the down-regulation of antiapoptotic Bcl-2 members (Bcl-2 and Bcl-xL) and IAP family proteins, the up-regulation of pro-apoptotic Bax protein and
\end{abstract}

Correspondence to: Dr Yung Hyun Choi, Department of Biochemistry, Dongeui University College of Oriental Medicine, Busan 614-052, Korea

E-mail: choiyh@deu.ac.kr

Key words: pectenotoxin-2, hepatocellular carcinoma, p53, apoptosis tumor necrosis factor-related apoptosis-inducing ligand (TRAIL)-receptor $1 /$ receptor 2 (DR4/DR5) and mitochondrial dysfunction. PTX-2 activated caspases (caspase-3, -8 and -9 ) and the blockade of caspase- 3 activity by the caspase-3 inhibitor prevented the PTX-2-induced apoptosis in Hep3B cells. Additionally, the transcription factor early growth response-1 (Egr-1) gene was transcriptionally activated and the levels of non-steroidal anti-inflammatory drugs (NSAID)-activated gene-1 (NAG-1) protein were also elevated in PTX-2-treated Hep3B cells. Although further studies are needed to prove that an increased expression of Egr-1 by PTX-2 directly leads to NAG-1 induction and then apoptosis induction in p53-deficient Hep3B cells, the results of this study suggest that PTX-2 may be a good candidate for the development of a potential anti-tumorigenic agent in p53deficient tumors.

\section{Introduction}

Apoptosis (programmed cell death), plays an important role in regulating the number of cells during development in the homeostatic cell turnover in adults and in many other settings. However, most cancer cells can block apoptosis, which allows them to survive despite the genetic and morphologic transformations. Apoptotic cells are characterized by several unique features, including cell shrinkage, chromatin condensation, DNA fragmentation, cell surface expression of phosphatidylserine and membrane blebbing (1-3). In general, apoptosis can be initiated in two ways: by an extrinsic or intrinsic pathway. Depending on the nature of the substance and the type of cells, apoptosis may take place via either pathway. In the former case, plasma membrane death receptors are involved. The apoptosis signal is provided by the interaction between the ligand and death receptor. Changes in the mitochondrial integrity by a broad range of physical and chemical stimuli, however, can trigger the intrinsic pathway of 
apoptosis (4-6). Besides the morphological and biological changes, other biomarkers and events could also be used for the precise determination of the type of apoptosis. Accumulating data indicate that many chemopreventive and/or chemotherapeutic agents can cause tumor cell death through the induction of apoptosis, which is the preferred way of managing cancer. Therefore, the induction of apoptotic cell death is an important mechanism in the anticancer properties of many anti-cancer drugs.

The tumor suppressor p53 gene plays a major role in preventing tumorigenesis, by responding to both cellular stress and DNA damage and the mutation of p53 is frequently associated with oncogenesis $(7,8)$. Intracellular concentrations of p53 are robustly increased by stresses such as DNA damage, ionizing radiation, UV radiation, hypoxia, growth factor withdrawal, oncogene activation and exposure to cytotoxic agents $(8,9)$. Numerous studies have demonstrated that p53 directly activates the transcription of a number of genes including cyclin-dependent kinase inhibitor p21 (WAF1/CIP1), the major mediator of p53 cell-cycle inhibitory capacity and the apoptotic genes $(9,10)$. However, it is not yet completely understood how the activation of p53 initiates apoptosis. In some cell lines, its activation leads to the induction of pro-apoptotic Bax expression, which allows the release of sequestered pro-apoptotic proteins and subsequent permeabilization of the outer mitochondrial membrane $(11,12)$. Pro-apoptotic Bax also antagonizes antiapoptotic $\mathrm{Bcl}-2$ and other anti-apoptotic molecules, facilitating apoptosis through this pathway. Thus, it is very important to point out that even p53-lacking cells undergo apoptosis when treated with some drugs, leading to the possibility that several other mechanisms may be taking place that need to be identified. For example, cell lines derived from hepatocellular carcinoma, such as Hep3B, have been shown to have mutations in the p53 gene (13), making them highly insensitive to drugs that act through p53-dependent apoptosis pathways. The opposite is observed in hepatoma cells such as HepG2, which have no reported mutations in p53 (14), being at least in this aspect, closer to normal hepatocytes and are a useful model for studies on chemotherapeutic drugs.

Previous studies indicate that marine organisms are proving to be a novel and rich source of bioactive compounds due to their potential pharmacological activities. Among them, marine sponges have been used as a main source for this study of hitherto unknown biological activities of natural marine products $(15,16)$. Investigations into components of marine organisms have proven that many are not general cytotoxic agents, but rather are targeted towards specific cellular or biochemical events and therefore hold strong potential as anti-microbial, anti-cancer or anti-inflammatory agents (17-19). Through the screening of marine natural compounds that inhibit cancer cell proliferation, we previously reported that pectenotoxin-2 (PTX-2) isolated from marine sponges, Poecillastra sp. and Jaspis sp., exhibited selective cytotoxicity against several cell lines (20) and activated an intrinsic pathway of apoptosis in p53-deficient tumor cells compared to those with functional p53 both in vitro and in vivo (21). However, the molecular mechanisms of its anti-proliferative action on malignant cell growth are not completely known. To further explore the mechanism of its anti-cancer activity and to test whether the status of p53 in liver cancer cells correlates with their chemosensitivities to PTX-2, we chose two wellknown hepatocarcinoma cell lines, p53-deficient HepG2 and p53-wild-type Hep3B. Our study revealed that Hep3B cells were much more susceptible to PTX-2 than HepG2 cells, which was connected with the induction of apoptotic cell death in Hep3B cells, though not in HepG2 cells. The apoptosis induced by PTX-2 in Hep3B cells was associated with the modulation of the Bcl-2 family, activation of caspases and loss of mitochondrial membrane potential (MMP, $\Delta \Psi_{\mathrm{m}}$ ). PTX-2 also activated the transcription factor early growth response-1 (Egr-1) gene expression in a transcriptional level and induced the tumor necrosis factor-related apoptosisinducing ligand (TRAIL)-receptor 1/receptor 2 (DR4/DR5) and the nonsteroidal anti-inflammatory drugs (NSAID)activated gene-1 (NAG-1).

\section{Materials and methods}

Cell culture and cell viability assay. Human hepatocarcinoma HepG2 and Hep3B cells were purchased from the American Type Culture Collection (Rockville, MD, USA). Both cell lines were cultured in Dulbecco's modified Eagle's medium (DMEM) containing 100 units/ml penicillin/streptomycin and supplemented with $10 \%$ heat-inactivated fetal bovine serum (FBS, Gibco BRL, Gaithersburg, MD, USA) at $37^{\circ} \mathrm{C}$ and $5 \%$ $\mathrm{CO}_{2}$. PTX-2 was prepared as described previously (20) and dissolved in dimethyl sulfoxide (DMSO) as a stock solution at $1 \mathrm{mg} / \mathrm{ml}$ concentration and stored in aliquots at $-20^{\circ} \mathrm{C}$. Measurement of cell viability was determined using the 3-(4,5dimethylthiazol-2-yl)-2,5-diphenyl-tetrazolium bromide (MTT, Sigma Chemical Co., St. Louis, MO, USA) assay, which is based on the conversion of MTT to MTT-formazan by mitochondrial enzyme.

Measurement of apoptosis by annexin-V FITC and PI double staining. The magnitude of the apoptosis elicited by PTX-2 treatment was determined using an Annexin-V fluorescein isothiocyanate (FITC) apoptosis detection kit (BD Pharmingen, San Diego, CA, USA). Briefly, the cells were washed with phosphate-buffered saline (PBS) and resuspended in annexin-V-binding buffer containing $10 \mathrm{mM}$ HEPES/NaOH, pH 7.4, $140 \mathrm{mM} \mathrm{NaCl}$ and $2.5 \mathrm{mM} \mathrm{CaCl}_{2}$, according to the manufacturer's protocol. Aliquots of the cells were incubated with annexin-V FITC, mixed and incubated for $15 \mathrm{~min}$ at room temperature in the dark. Propidium iodide (PI) at a concentration of $5 \mu \mathrm{g} / \mathrm{ml}$ was added to identify the necrotic cells. The apoptotic cells $\left(\mathrm{V}^{+} / \mathrm{PI}\right)$ were measured by a fluorescence-activated cell sorter analysis in flow cytometry (Becton Dickinson, San Jose, CA, USA).

Nuclear staining with DAPI. After treating the cells with PTX-2 for the indicated times, the cells were harvested, washed in ice-cold PBS and fixed with $3.7 \%$ paraformaldehyde (Sigma) in PBS for $10 \mathrm{~min}$ at room temperature. The fixed cells were washed with PBS and stained with a 4,6-diamidino-2phenylindile (DAPI) solution for $10 \mathrm{~min}$ at room temperature. The cells were washed two more times with PBS and analyzed via a fluorescent microscope (Carl Zeiss, Germany). 
$R N A$ extraction and reverse transcription-PCR. The total RNA was prepared using an RNeasy kit (Qiagen, La Jolla, CA, USA) and primed with random hexamers to synthesize the complementary DNA using AMV reverse transcriptase (Amersham Corp., Arlington Heights, IL, USA) according to the manufacturer's instructions. A polymerase chain reaction (PCR) was carried out using a Mastercycler (Eppendorf, Hamburg, Germany) with the primers. The primer sequences were as follows: Egr-1 forward (5'-CCC TAA GCT GGA GGA GAT GAT G-3'), Egr-1 reverse (5'-TCA TGC TCA CTA GGC CAC TGA C-3'), glyceraldehyde-3-phosphate dehydrogenase (GAPDH) forward (5'-CGG AGT CAA CGG ATT TGG TCG TAT-3') and GAPDH reverse (5'-AGC CTT CTC CAT GGT GGT GAA GAC-3'). The following conditions were used for the PCR reactions: $1 \times\left(94^{\circ} \mathrm{C}\right.$ for $3 \mathrm{~min}) ; 35 \mathrm{x}\left(94^{\circ} \mathrm{C}\right.$ for $45 \mathrm{sec} ; 58^{\circ} \mathrm{C}$ for $45 \mathrm{sec}$; and $72^{\circ} \mathrm{C}$ for $1 \mathrm{~min})$ and $1 \mathrm{x}\left(72^{\circ} \mathrm{C}\right.$ for $\left.10 \mathrm{~min}\right)$. The amplification products obtained by PCR were separated electrophoretically on a $1 \%$ agarose gel and visualized by ethidium bromide (EtBr, Sigma) staining.

Gel electrophoresis and Western blot analysis. The cells were harvested, lysed and the protein concentrations were quantified using a Bio-Rad protein assay (Bio-Rad Lab., Hercules, CA, USA), according to the procedure reported by the manufacturer. For Western blot analysis, an equal amount of protein was subjected to electrophoresis on SDSpolyacrylamide gel and transferred to a nitrocellulose membrane (Schleicher \& Schuell, Keene, NH, USA) by electroblotting. The blots were probed with the desired antibodies for $1 \mathrm{~h}$, incubated with the diluted enzyme-linked secondary antibody and visualized by enhanced chemiluminescence (ECL) according to the recommended procedure (Amersham). The primary antibodies were purchased from Santa Cruz Biotechnology Inc. (Santa Cruz, CA, USA) and Calbiochem (Cambridge, MA, USA). The peroxidase-labeled donkey anti-rabbit immunoglobulin and peroxidase-labeled sheep anti-mouse immunoglobulin were purchased from Amersham.

Measurement of the loss of mitochondrial membrane potential $\left(M M P, \Delta \Psi_{m}\right)$. To measure the MMP, the dualemission potential-sensitive probe, 5,5 V, 6,6 V-tetrachloro-1,1 V,3,3 V-tetraethyl-imidacarbocyanine iodide (JC-1, Sigma), was used. After treatment with PTX-2, the cells were scraped from the bottom of the wells and aliquots of $5 \times 10^{5}$ cells were placed into FACS tubes. Cells were then stained with $2 \mathrm{mg} / \mathrm{l}$ $\mathrm{JC}-1$ at $37^{\circ} \mathrm{C}$ for $20 \mathrm{~min}$ and then analyzed using flow cytometry (Becton Dickinson).

Measurement of caspase activity. The enzymatic activities of the caspases induced by PTX-2 were assayed using colorimetric assay kits according to the manufacturer's protocol (R\&D Systems, Minneapolis, MN, USA). Briefly, the cells were lysed in a lysis buffer for $30 \mathrm{~min}$ on an ice bath. The lysed cells were centrifuged at $12,000 \mathrm{x} \mathrm{g}$ for $10 \mathrm{~min}$ and $100 \mu \mathrm{g}$ of the protein was incubated with $50 \mu \mathrm{l}$ of a reaction buffer and $5 \mu \mathrm{l}$ of the colorimetric tetrapeptides, AspGlu-Val-Asp (DEVD)-p-nitroaniline (pNA) for caspase-3, IleGlu-Thr-Asp (IETD)-pNA for caspase-8 and Leu-Glu-His-Asp
(LEHD)-pNA for caspase-9, respectively, at $37^{\circ} \mathrm{C}$ for $2 \mathrm{~h}$. The optical density of the reaction mixture was quantified spectrophotometrically at a wavelength of $405 \mathrm{~nm}$.

Transfections and luciferase assay for the detection of Egr-1 activity. The human Egr-1 promoter-containing plasmids were generously provided by Dr K.W. Kim (College of Pharmacy, Seoul National University, Korea) (22). For transfection, in brief, cells were plated onto 6-well plates at a density of $3 \times 10^{5}$ cells/well. The cells were washed twice with a serum-free Optimem medium (Gibco BRL) and then $500 \mu 1$ of fresh serum-free medium was added. The plasmid/polymer complex was added to each dish and then incubated for $10 \mathrm{~h}$ at $37^{\circ} \mathrm{C}$ in a $5 \% \mathrm{CO}_{2}$ incubator. After $10 \mathrm{~h}, 1 \mathrm{ml}$ of fresh Optimem medium containing $20 \%$ FBS was added to each well and treated with $10 \mathrm{ng} / \mathrm{ml}$ PTX-2 for the indicated times. Luciferase activity was measured using a TD-20/20 luminometer (Turner Designs Instrument Co., San Francisco, CA, USA).

\section{Results}

Inhibition of cell viability by PTX-2 in p53-deficient Hep3B cells. We used an MTT assay to evaluate the anti-proliferative activity of PTX-2 on HepG2 and Hep3B cells and found that p53-deficient Hep3B cells were much more susceptible than HepG2 cells, which contain wild-type p53 (Fig. 1A). After $24 \mathrm{~h}$ of treatment with $10 \mathrm{ng} / \mathrm{ml}$ PTX-2 (no toxic effect was observed after $8 \mathrm{~h}$ in both cell lines), most HepG2 cells were viable, whereas Hep3B showed $~ 50 \%$ of viability. When treated with $10 \mathrm{ng} / \mathrm{ml}$ PTX-2 for 36 and $48 \mathrm{~h}$ incubation, the cell viability of Hep3B was 20 and $8 \%$, respectively. However, there was no significant inhibition effect on HepG2 cells. Additionally, treated Hep3B cells with PTX-2 were rounded up and more dispersed without aggregation in a time-dependent manner. In contrast, there was no markedly morphological change in PTX-2 treated HepG2 cells (Fig. 1C).

Induction of apoptosis by PTX-2 in p53-deficient Hep3B cells. To investigate whether the viability decrease in Hep3B cells was due to the induction of apoptosis, nuclear morphology of PTX-2-treated cells was analyzed with DAPI staining. As shown in Fig. 1D, the nuclei of Hep3B cells, but not in HepG2 cells, exposed to PTX-2 exhibited condensed and fragmented chromatin and the effects were dose-dependent. Therefore, flow cytometry analysis with annexin V and PI staining was used to determine the magnitude of apoptosis elicited by PTX-2. As shown in Fig. 1B, the annexin V-positive cells were increased time-dependently in the PTX-2-treated Hep3B cells compared with the untreated control cells. Hep3B cells treated with $10 \mathrm{ng} / \mathrm{ml} \mathrm{PTX}$ for 36 and $48 \mathrm{~h}$, the apoptosis was 25 and $30 \%$, respectively, however, there was no significant increase in HepG2 cells (Fig. 1B). These results demonstrated that the cytotoxic effects observed in response to PTX-2 are associated with the induction of apoptotic cell death in p53-deficient Hep3B cells.

Modulation of Bcl-2 and IAP family proteins by PTX-2 in p53-deficient Hep3B cells. To elucidate mechanisms 
A)

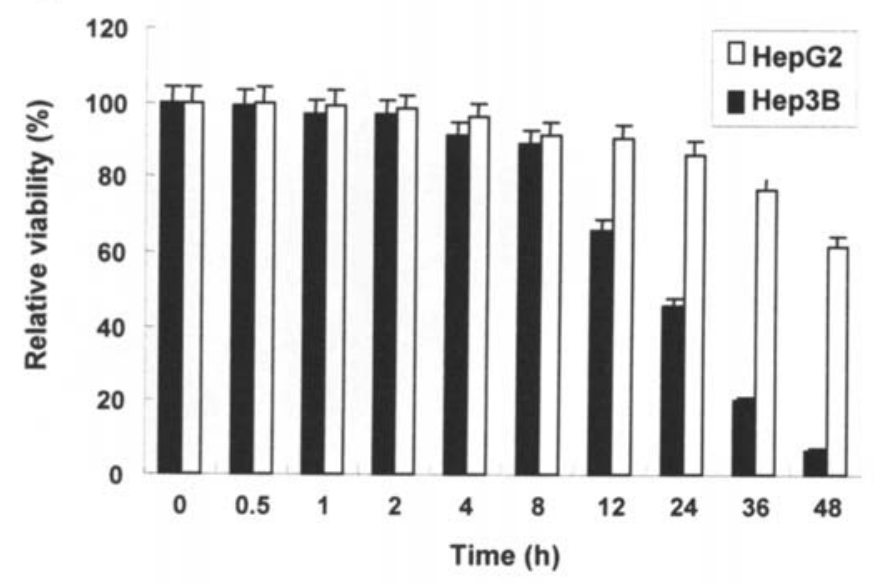

Time (h)

C)

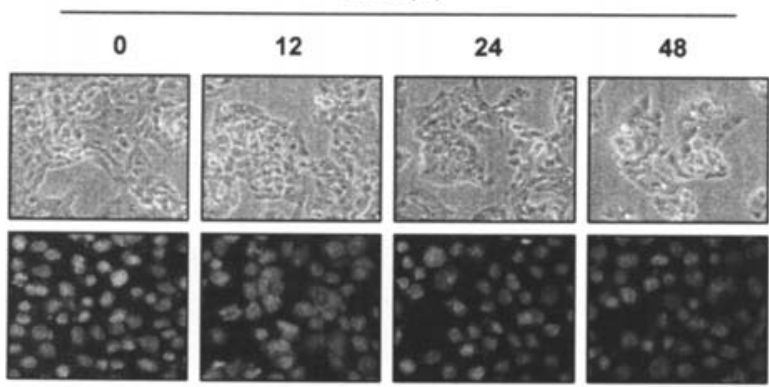

HepG2
B)
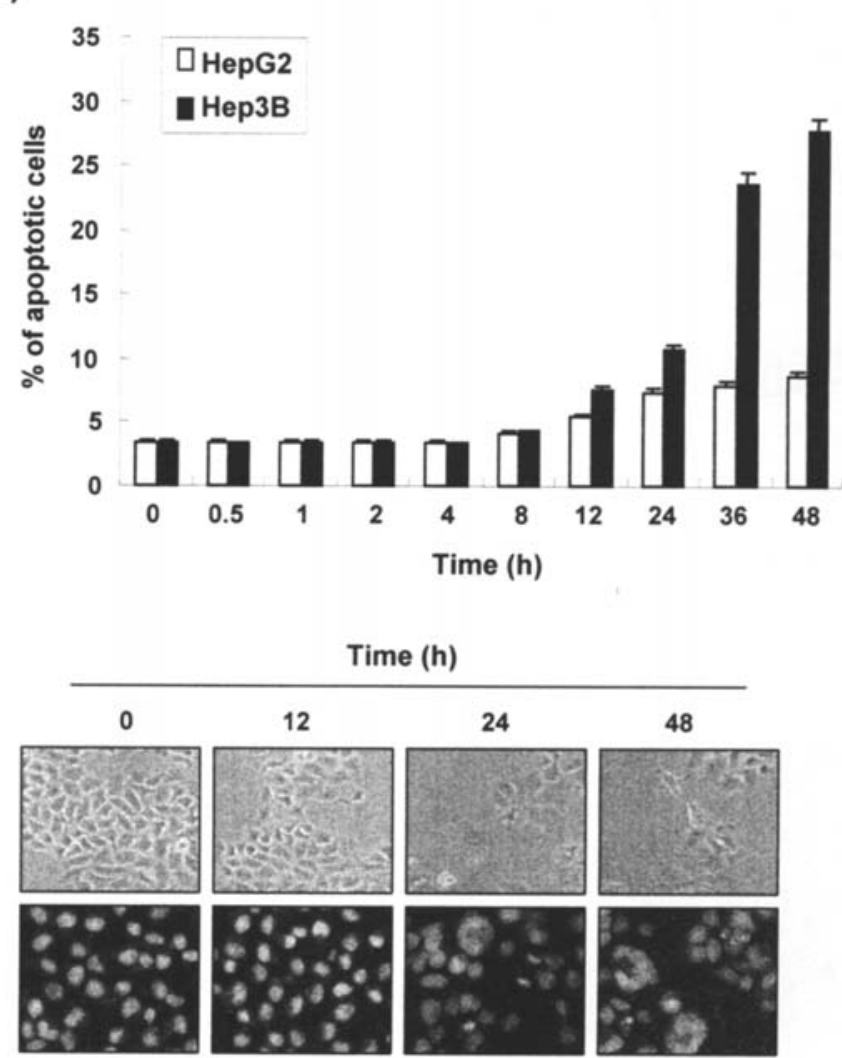

Hep3B

Figure 1. Inhibition of cell viability and induction of apoptosis by pectenotoxin-2 (PTX-2) in p53-deficient hepatocarcinoma Hep3B cells. HepG2 and Hep3B cells were seeded at an initial density of $2.5 \times 10^{5}$ cells per $60-\mathrm{mm}$ plate, incubated for $24 \mathrm{~h}$ and treated with $10 \mathrm{ng} / \mathrm{ml} \mathrm{PTX}-2$ for the indicated times. (A) The level of cell viability was measured using MTT assay. Each point represents the mean \pm SD of three independent experiments. (B) The cells grown under the same conditions as (A) were collected and stained with FITC-conjugated annexin-V and PI for flow cytometry analysis. The apoptotic cells were determined by counting the $\%$ of annexin $\mathrm{V}(+), \mathrm{PI}(-)$ cells and the $\%$ of annexin $\mathrm{V}(+), \mathrm{PI}(+)$ cells. The results are expressed as the mean \pm SD of three independent experiments. (C) After incubation with $10 \mathrm{ng} / \mathrm{ml} \mathrm{PTX-2} \mathrm{for} \mathrm{the} \mathrm{indicated} \mathrm{times,} \mathrm{the} \mathrm{cells} \mathrm{were} \mathrm{sampled} \mathrm{and} \mathrm{examined} \mathrm{by} \mathrm{an} \mathrm{inverted} \mathrm{microscope.}$ Magnification, x200. (D) The cells grown under the same conditions as (C) were fixed, stained with DAPI and the nuclear morphology was photographed with fluorescence using a blue filter. Magnification, $\mathrm{x} 400$.

underlying PTX-2-induced apoptosis, we investigated the levels of Bcl-2 and IAP family proteins by Western blotting. When Hep3B cells were treated with PTX-2, a clear decrease in anti-apoptotic Bcl-2 and Bcl-xL protein expression was observed in a time-dependent manner (Fig. 2). In the case of pro-apoptotic protein Bax, there was a time-dependent upregulation observed in Hep3B cells treated with PTX-2. However, PTX-2 did not significantly affect the Bcl-2 family proteins in HepG2 cells (Fig. 2). The levels of IAP family proteins such as XIAP, cIAP-1 and cIAP-2 after PTX-2 treatment were down-regulated in Hep3B cells treated with PTX-2 in a time-dependent manner. Though the XIAP expression was slightly down-regulated by PTX-2 treatment, we could not detect any change in either cIAP-1 or cIAP-2 HepG2 cells.

Activation of caspase by PTX-2 in p53-deficient Hep3B cells. The expression levels and activities of caspase- $3,-8$ and -9 in HepG2 and Hep3B cells that had been exposed to PTX-2 were measured in order to determine if PTX-2-induced apoptosis is associated with the activation of caspase. As shown in Fig. 3A, Western blot data showed that the levels of pro-caspase-3, -8 and -9 proteins were slightly decreased or remained unchanged in PTX-2-treated Hep3B cells. However, the levels of active subunits of the caspase expression were increased in a timedependent manner. In order to further quantify the proteolytic activation of caspases in Hep3B cells, the lysates equalized for protein from the cells treated with PTX-2 were assayed for their activity using an in vitro assay with a colorimetric assay kit. We found that PTX-2 caused a time-dependent increase in proteolytic activities of caspases, especially caspase-3 (Fig. 3B). However, the expression levels and activities of those caspases in the PTX-2-treated HepG2 cells were relatively unaffected.

Inhibition of PTX-2-induced apoptosis by the caspase-3 inhibitor. In order to show that the activation of caspase- 3 is a key step in the PTX-2-induced end-stage apoptotic events in Hep3B cells, cells were pretreated with z-DEVD-fmk $(50 \mu \mathrm{M})$, a cell-permeable caspase- 3 inhibitor, for $1 \mathrm{~h}$, followed by a treatment with $10 \mathrm{ng} / \mathrm{ml}$ PTX-2 for $24 \mathrm{~h}$. The blockade of the caspase-3 activity by a pre-treatment of the cells with zDEVD-fmk prevented the PTX-2-induced chromatin condensation, inhibition of cell viability and increase in the sub-G1 population suggesting that PTX-2-induced apoptosis is associated with caspase-3 activation (Fig. 4). 


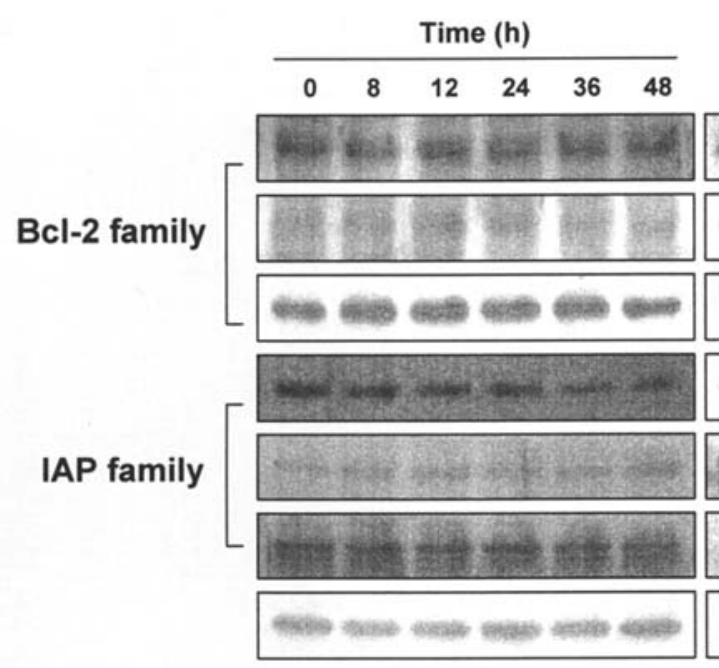

HepG2

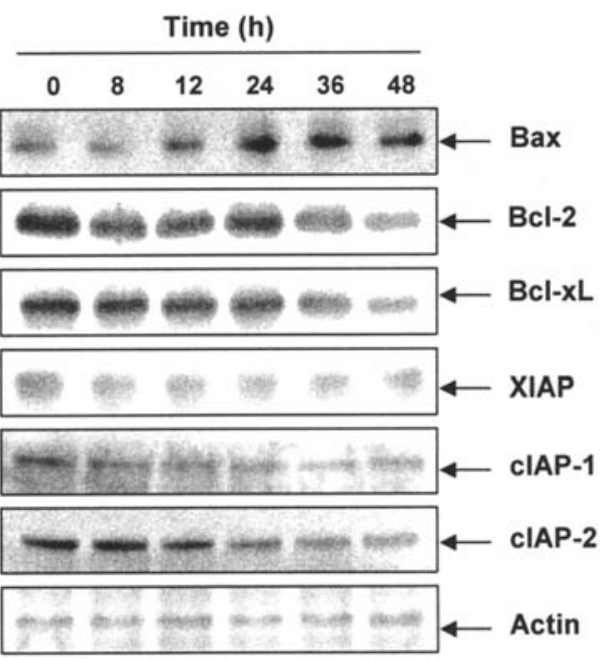

Нер3B

Figure 2. Effects of PTX-2 on the expression of Bcl-2 and IAP family proteins in HepG2 and Hep2B cells. The cells were incubated with 10 ng/ml PTX-2 for the indicated times, lysed and equal amounts of proteins were then separated by SDS-polyacrylamide gels and transferred to nitrocellulose membranes. The membranes were probed with the indicated antibodies and detected by ECL. To confirm an equal loading, the blots were stripped of the bound antibodies and reprobed with the anti-actin antibody.

A)

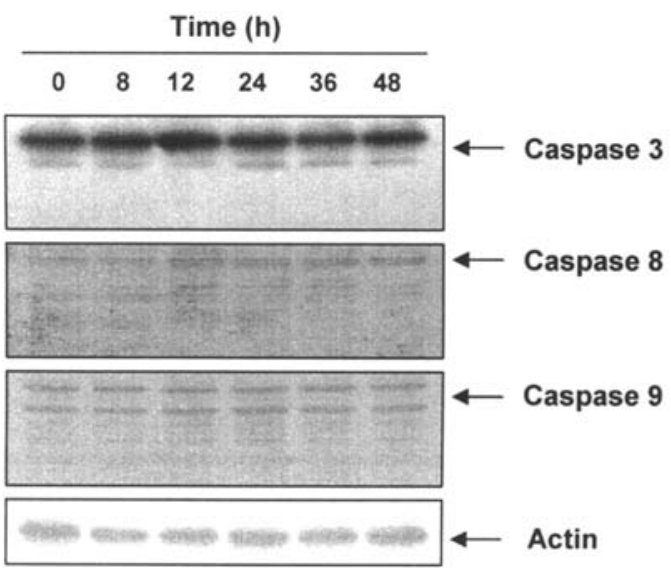

B)

HepG2

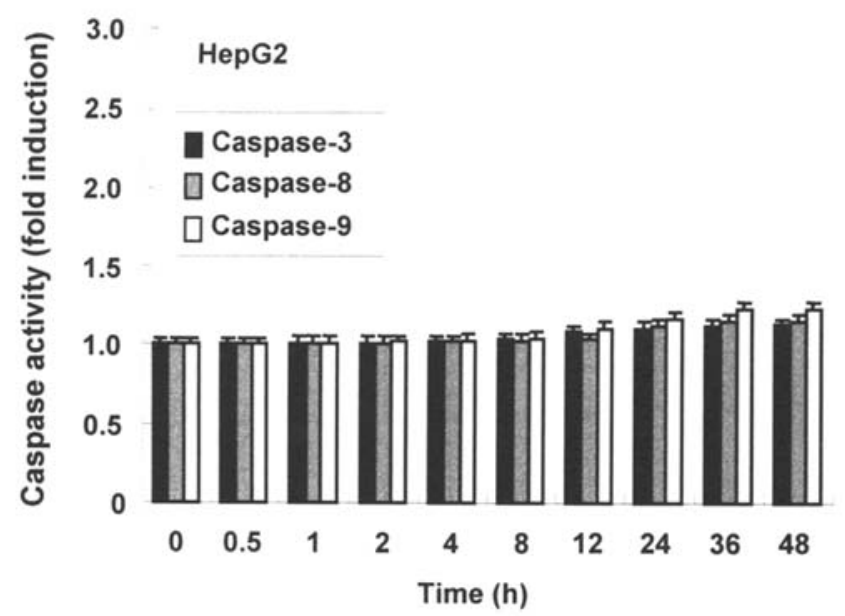

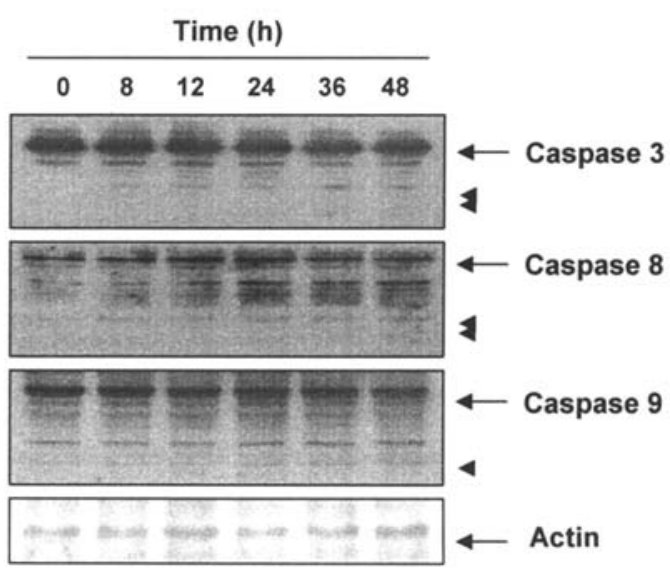

Нер3B

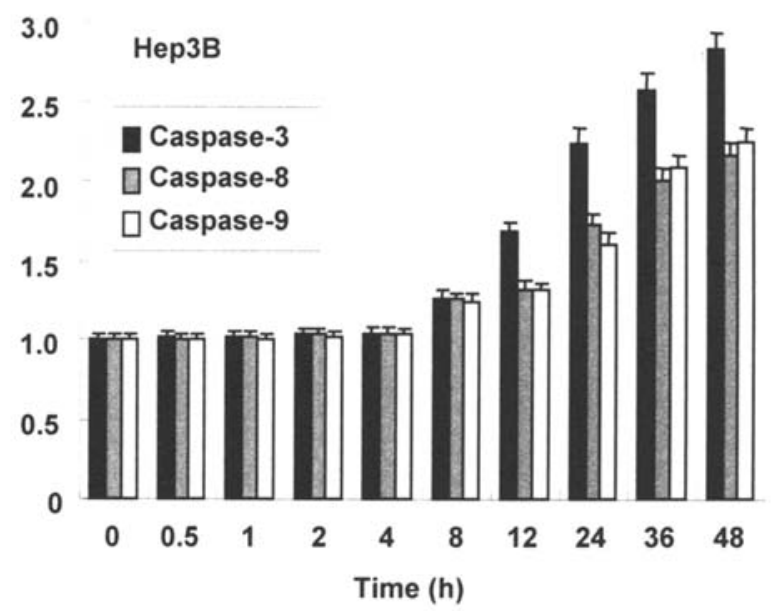

Figure 3. Activation of caspases by PTX-2 in p53-deficient Hep3B cells. (A) After treatment with $10 \mathrm{ng} / \mathrm{ml}$ of PTX-2 for the indicated times, the cells were lysed and the cellular proteins were separated by SDS-polyacrylamide gels and transferred into nitrocellulose membranes. The membranes were probed with the anti-caspase-3, -8 and -9 antibodies. The proteins were visualized using an ECL detection system. Actin was used as the internal control. (B) The cell lysates from the cells treated with PTX-2 were assayed for in vitro caspase-3, -8 and -9 activity using DEVD-pNA, IETD-pNA and LEHD-pNA, respectively, as substrates. The released fluorescent products were measured. The results are expressed as the mean \pm SD of three independent experiments. 
A)

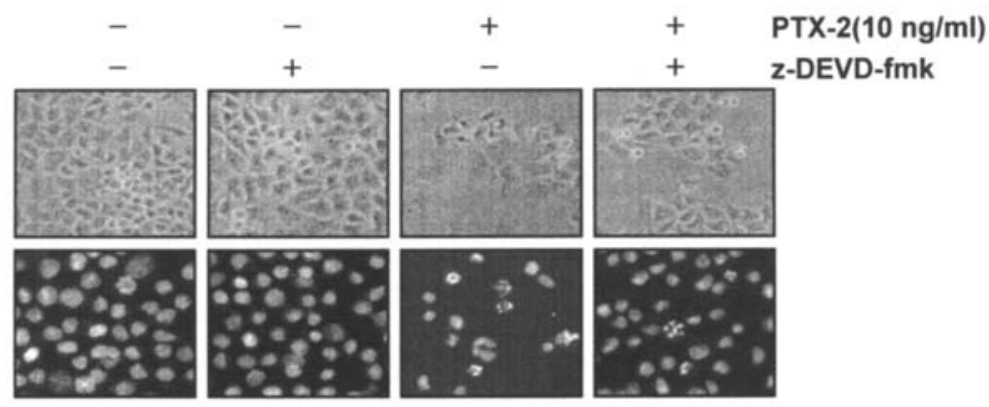

B)

C)
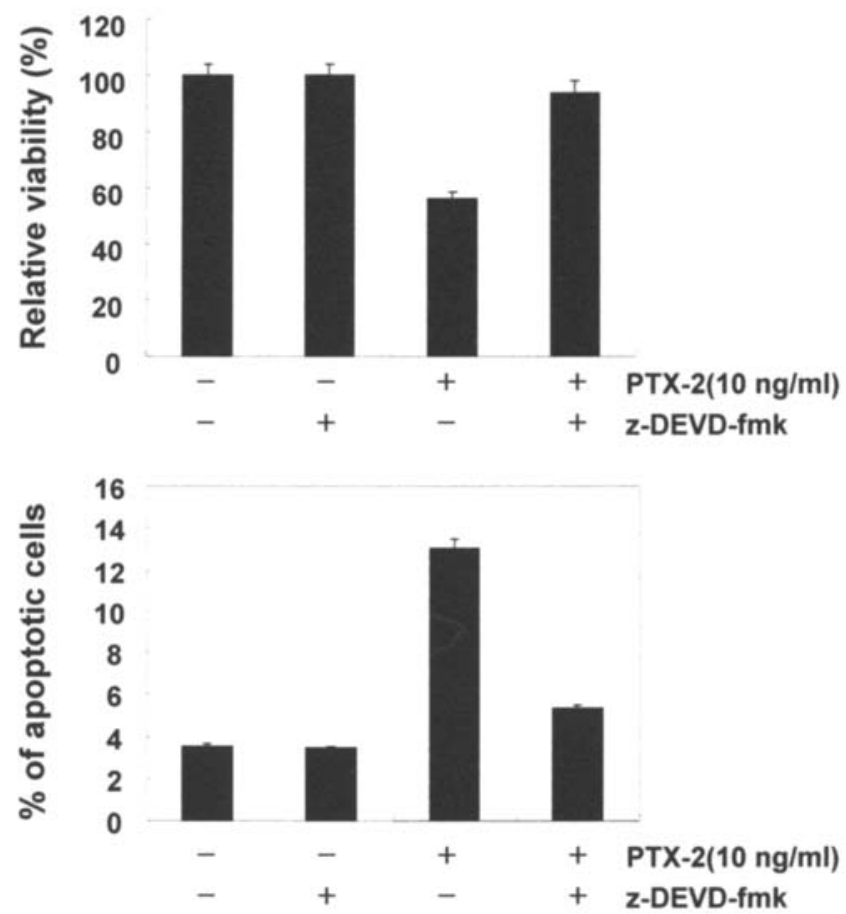

Figure 4. Inhibition of PTX-2-induced apoptosis by caspase-3 inhibitor, z-DEVD-fmk, in Hep3B cells. (A) Hep3B cells were treated with z-DEVD-fmk (50 $\mu$ M) for $1 \mathrm{~h}$ before a challenge with $10 \mathrm{nM}$ PTX-2 for $24 \mathrm{~h}$. The cells were observed under inverted microscopy (magnification, x200) or stained with DAPI for $10 \mathrm{~min}$ and photographed with a fluorescent microscope using a blue filter (magnification, $\mathrm{x} 400$ ). (B and C) The cells were grown under the same conditions as (A) and evaluated for cell viability and the sub-G1 DNA content using MTT assay and a flow cytometer, respectively. The data are reported as a mean \pm SD of three independent experiments.

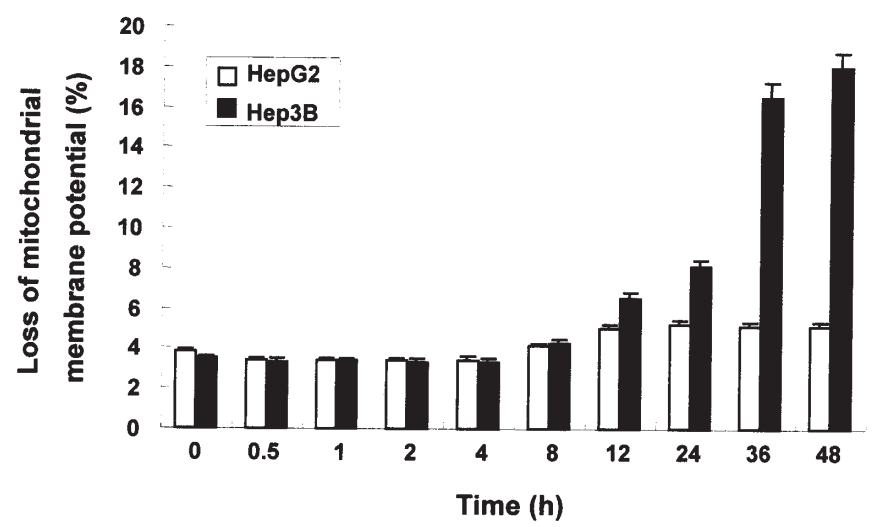

Figure 5. Effect of PTX-2 treatment on mitochondrial membrane potential (MMP, $\Delta \Psi_{\mathrm{m}}$ ) in HepG2 and Hep3B cells. Cells were treated with $10 \mathrm{ng} / \mathrm{ml}$ PTX-2 for the indicated times to follow the extent of apoptosis by determination of MMP using JC-1 reagent. Cells were analyzed on a FACScan cytometer and the data shown are representative of three independent experiments with similar findings. The results are expressed as the mean $\pm \mathrm{SD}$ of three independent experiments.
Loss of MMP by PTX-2 in p53-deficient Hep3B cells. In order to determine whether PTX-2-induced apoptosis is associated with the loss of MMP, we measured MMP in PTX-2-treated HepG2 and Hep3B cells using a fluorescent cationic dye JC-1. As shown in Fig. 5, the loss of MMP induced by PTX-2 increased in Hep3B cells after $8 \mathrm{~h}$ and the values of MMP loss in Hep3B cells reached $\sim 15-18 \%$ at 36 and $48 \mathrm{~h}$, respectively, evidencing the increased depolarization of the MMP with increased PTX-2 treatment times. However, when HepG 2 cells were cultured with PTX-2, a significant enhancement in PTX-2-induced loss of MMP was not noted. These data indicated that PTX-2 induced mitochondrial dysfunction, which eventually activated the caspase cascade in the apoptosis signaling of p53-deficient Hep3B cells.

Activation of Egr-1 in PTX-2-treated p53-deficient Hep3B cells. To investigate whether PTX-2-induced growth inhibition and apoptosis is associated with Egr-1 activation, HepG2 and Hep3B cells were treated with PTX-2 for various times and the mRNA and protein levels were measured by RT-PCR and 
A)

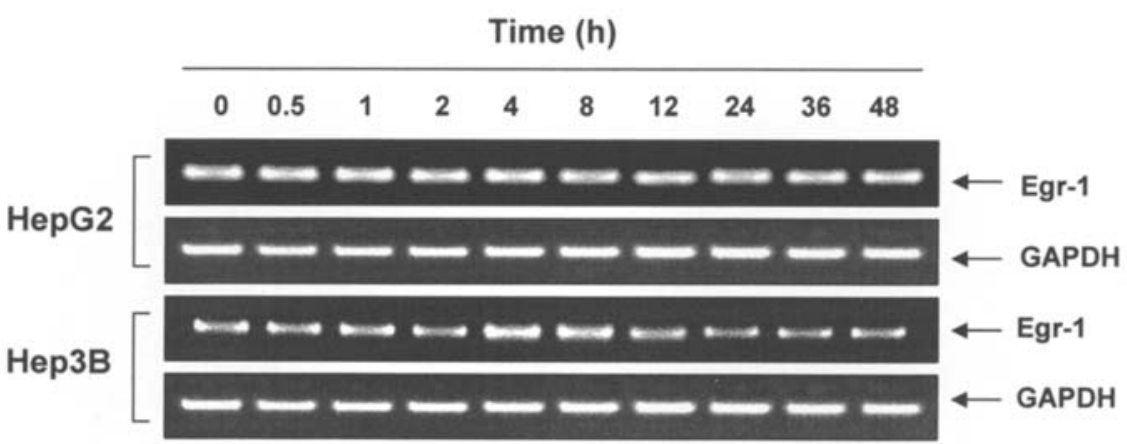

B)

Time (h)

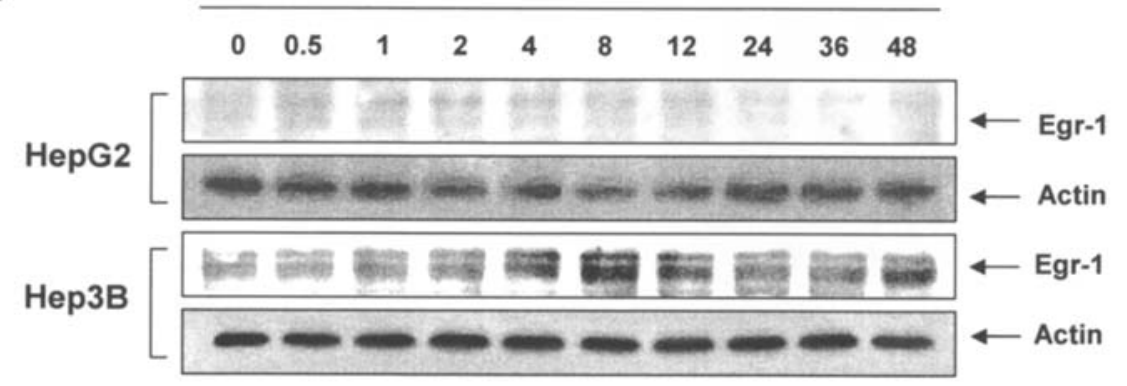

C)

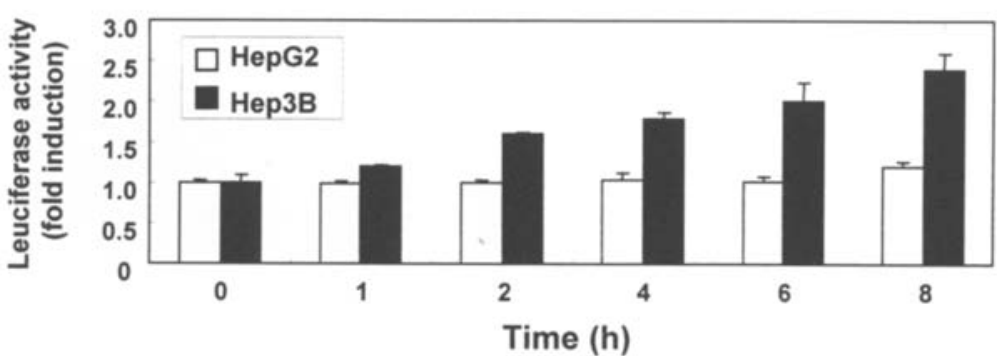

Figure 6. Activation of Egr-1 by PTX-2 in p53-deficient Hep3B cells. (A) HepG2 and Hep3B cells were treated with 10 ng/ml PTX-2 for the indicated times and the total RNA was isolated and reverse-transcribed. The resulting cDNAs were subjected to PCR with the Egr-1 and GAPDH primers and the reaction products were subjected to electrophoresis in a 1\% agarose gel and visualized by EtBr staining. GAPDH was used as the internal control. (B) The cells under the same conditions as (A) were lysed and equal amounts of proteins were then separated by SDS-polyacrylamide gels and transferred to nitrocellulose membranes. The membranes were probed with the Egr-1 antibody and detected by ECL. To confirm equal loading, the blot was stripped of the bound antibody and reprobed with the anti-actin antibody. (C) Cells were transfected with Egr-1-luc and then treated with $10 \mathrm{ng} / \mathrm{ml}$ PTX-2. The cells were collected and luciferase activity was determined as described under Materials and methods. Results are expressed as a mean \pm SD for three determinations for each treatment group.

Western blot analyses. As shown in Fig. 6A and B, PTX-2 induced the expression of Egr-1 mRNA and protein in Hep3B cells, however, the temporal expression of mRNA and proteins is different. Egr-1 mRNA is maximally induced within $4 \mathrm{~h}$ after treatment with PTX-2 and levels then decline 8 to $48 \mathrm{~h}$ after treatment, whereas the induction of Egr-1 protein increases after the $8 \mathrm{~h}$ treatment period. It was also investigated whether the effects of the PTX-2 on transactivation in cells transfected with constructs containing the Egr-1 promoter insert. As shown in Fig. 6C, PTX-2 treatment induced transactivation in only Hep3B cells transfected with Egr-1 in a time-dependent manner.

Induction of NAG-1 and DR4/5 by PTX-2 in p53-deficient Hep3B cells. Since previous reports have linked the apoptotic activity of anti-cancer drugs to the induction of both Egr-1 and NAG-1, it was also compared with the effect of PTX-2 on the protein levels of NAG-1 in HepG2 and Hep3B cells. The results in Fig. 7 show that PTX-2 time-dependently induced the expression NAG-1 protein in Hep3B cells, however, the levels of NAG-1 protein in HepG2 cells remained unchanged. Then, we attempted to see the involvement of the death receptors such as DR4 and DR5 in PTX-2-induced apoptosis in Hep3B cells. As shown in Fig. 7, the immunoblotting data indicate that the levels of DR4 protein were induced within $2 \mathrm{~h}$ after treatment and continuously expressed within $48 \mathrm{~h}$ and the levels of DR5 were increased after $24 \mathrm{~h}$ of treatment with PTX-2 in p53-deficient Hep3B cells. However, the expression levels of DR4 and DR5 in the PTX-2-treated HepG2 cells were relatively unaffected.

\section{Discussion}

Generally, wild-type-p53-containing cells, such as HepG2, are more susceptible to cytotoxic chemical agents and radiation, closely resembling what is observed in non-tumorigenic 


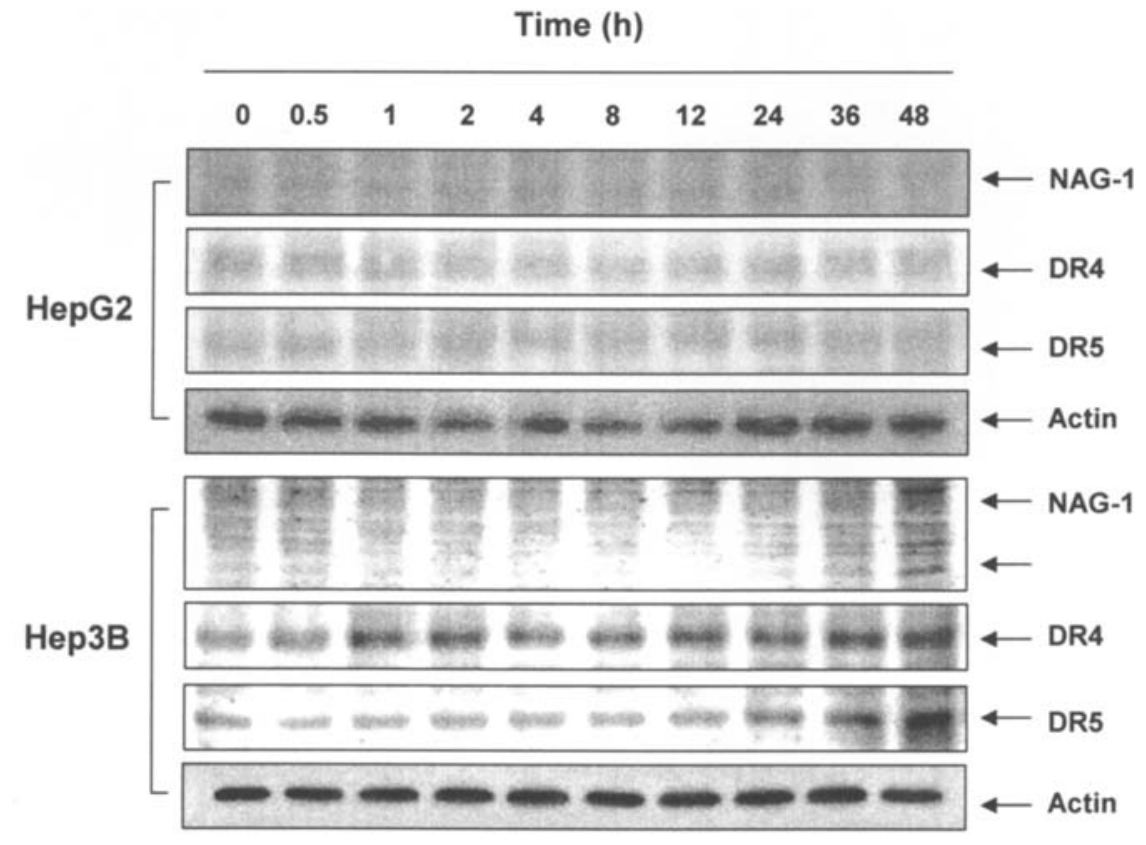

Figure 7. Effects of PTX-2 on the levels of DR4, DR5 and NAG-1 expression in HepG2 and Hep2B cells. The cells were incubated with $10 \mathrm{ng} / \mathrm{ml}$ PTX-2 for the indicated times, lysed and equal amounts of proteins were then separated by SDS-polyacrylamide gels and transferred to nitrocellulose membranes. The membranes were probed with the indicated antibodies and detected by ECL. Actin was used as the internal control.

cells. On the other hand, cells containing deletions or mutations in $\mathrm{p} 53$, such as Hep3B, are normally more resistant to drugs $(13,14)$. However, in the present study, PTX-2 was markedly toxic to p53-deficient Hep3B cells whereas HepG2 cells were much more resistant to PTX-2, which suggests that PTX-2 acts by a cytotoxic mechanism that seems to be p53-independent. The cytotoxic effects of PTX-2 in Hep3B cells were associated with the induction of apoptotic cell death confirmed by the characteristic morphological changes i.e. chromatin condensation and annexin-V-based assay (Fig. 1). Our previous report also showed that PTX-2 induced a more toxic effect on $\mathrm{p} 53$-deficient cancer cells both in vitro and in vivo than wild-type-p53-containing cancer cells, strengthening the idea that p53 was not necessary for the toxicity mediated by this compound (21), although the mechanisms that could explain these observations remain to be clarified. Therefore, to test why p53-deficient cancer cells are more chemosensitive to PTX-2, we compared the cellular responses of Hep3B and HepG2 after treatment with PTX-2.

In general, there are two main apoptosis pathways mediated according to their initiator caspase: the death receptor (extrinsic) pathway/caspase- 8 and the mitochondrial (intrinsic) pathway, in which various signals can trigger the release of harmful proteins by mitochondria into the cytoplasm, leading to the activation of caspase- 9 and the downstream cleavage of caspases such as caspase-3, -7 or -6 (3-6). The death receptor (extrinsic) pathway is triggered by ligand-induced aggregation of death receptors, such as Fas and DR4/5, whereas the mitochondrial (intrinsic) pathway is activated in response to cytotoxic drug-induced cellular stress. Mitochondria are involved in a variety of key events leading to apoptosis, such as the release of caspase activators, changes in electron transport, loss of MMP, the production of reactive oxygen species and participation in the regulation of Bcl-2 family proteins $(3,6,23)$. In the present study, we characterized the apoptotic pathway induced by PTX-2 and observed that the levels of anti-apoptotic Bcl-2 and $\mathrm{Bcl}-\mathrm{xL}$ protein expression were down-regulated in Hep3B but not in HepG2 cells. The pro-apoptotic Bax expression, on the other hand, was markedly up-regulated in Hep3B in a time-dependent manner, thus shifting the $\mathrm{Bax} / \mathrm{Bcl}-2$ and $\mathrm{Bax} / \mathrm{Bcl}-\mathrm{xL}$ ratio in favor of apoptosis (Fig. 2). The PTX-2 treatment was able to downregulate the expression of IAP family proteins, inhibitors of caspases, such as XIAP, cIAP-1 and cIAP-2 (Fig. 2). This compound also caused the proteolytic activation of caspases such as caspases-3, -8 and -9 in Hep3B cells, though not in HepG2 cells in a time-dependent manner (Fig. 3). However, under the same conditions, z-DEVD-fmk, a specific caspase-3 inhibitor, prevented the PTX-2-induced apoptosis by blocking not only the morphological changes, but also the inhibition of cell viability (Fig. 6). This indicates that caspase-3 plays an important role in PTX-2-induced apoptosis in p53-deficient Hep3B cells and PTX-2 induces apoptosis of Hep3B cells in caspase-dependent pathways. In the intrinsic pathway, MMP can be regulated by Bcl-2 family proteins $(6,23)$. These proteins are capable of forming either homo-oligomers or heterodimers with one another and appear to play distinct roles in governing MMP. Pro-apoptotic Bax, which can form homo-oligomers in the outer mitochondrial membrane in response to apoptotic stimuli, constitutes a gateway for outer mitochondrial membrane permeabilization. By contrast, antiapoptotic Bcl-2 can block MMP induced by Bax (23). As shown in Fig. 5, we observed that PTX-2 increased the loss of MMP in p53-deficient Hep3B cells without changing in HepG2 cells. These results indicate that PTX-2 activates caspase- 3 by increasing permeability of mitochondria membrane and thereby activating capase-9. We also found that PTX-2 induced the levels of DR4 and DR5 (Fig. 7), suggesting that the increase in DR4/5 and Bax levels probably contributed to the activation of caspase- 8 in Hep3B cells. 
NAG-1, as a novel molecular target of anti-carcinogenic agents, has recently been actively investigated. NAG-1 is a distant member of the transforming growth factor- $\beta$ (TGF- $\beta$ ) superfamily that has shown vital anti-tumorigenic activity and was identified from the cyclooxygenase-2 (COX-2) inhibitor indomethacin-treated HCT-116 colon cancer cells (24). However, NAG-1 induction in colon cancer cells by NSAID treatment would induce apoptosis and lead to a cyclooxygenase (COX)-independent anti-tumorigenic effect (25). Jang et al (26) suggested that overexpression of the death receptor would couple with NAG-1 induction to cause apoptosis. Moreover, ectopic expression of NAG-1 induced apoptosis through the induction of DR4 and DR5 expression in gastric cancer cells (26). Besides NSAID, other novel pro-apoptotic and antitumorigenic agents that also cause NAG-1 overexpression suggesting pro-apoptotic activity of NAG-1 may provide a molecular basis in explaining chemopreventive agentmediated anti-tumorigenesis (27-29). Nevertheless, the knowledge that NAG-1 is an important target of NSAID and other novel chemotherapeutic agents, the mechanism of its regulation is not clearly understood. Several upstream transcriptional factors have been suspected of causing the induction of NAG-1 in response to drug treatments. One of the candidates involved in the regulation is p53. NAG-1 promoter has two p53 binding sites and Wilson et al (30) reported that genistein, a naturally occurring isoflavonoid found in soy products, possesses a p53-dependent induction of NAG-1 in colorectal cancer cells. However, epicatechin gallate, one of the catechins in green tea, was reported to induce NAG-1 expression in the same colorectal cancer cell lines via a p53-independent activation of the activating transcription factor ATF-3 (31). On the other hand, Baek et al (32) reported that troglitazone (a peroxisome proliferatoractivated receptor- $\gamma$ ligand)-induced expression of NAG- 1 is essentially regulated by the increased expression of the transcription factor Egr-1, which is a member of the immediate-early gene family. They also demonstrated that two Egr-1 binding sites have been identified in transactivating NAG-1 expression, of which mutation of these sites could cause a dramatic reduction of NAG-1 promoter activity (32). Egr-1 is involved in the regulation of cell growth and differentiation in response to signals such as mitogens, growth factors and stress stimuli (33-35). Egr-1 has been proposed as a tumor suppressor gene and its induction is both p53dependent and p53-independent. Recently, Lim et al (36) reported that quercetin, a flavonoid molecule ubiquitously present in nature, induced the expression of NAG-1 through Egr-1 and p53 transactivation, during quercetin-induced apoptosis of human colon carcinoma cells. Thus, we further examined whether or not the involvement of Egr-1 and NAG-1 induction during PTX-2 induced apoptosis in p53deficient Hep3B cells. In the present study, PTX-2 markedly up-regulated the levels of DR4 and DR5 in p53-deficient Hep3B cells (Fig. 7), which was associated with not only the transactivation of Egr-1 but also the induction of NAG-1 protein (Fig. 6). Thus, our results in part suggest that the induction of Egr-1 and NAG-1 seems to be critical for PTX-2induced apoptosis in a p53-independent manner.

In summary, we have demonstrated that PTX-2 markedly inhibits p53-deficient Hep3B hepatocellular carcinoma cell growth and induces apoptosis whereas p53-wild-type HepG2 cells were much more resistant to PTX-2. These results suggest that PTX-2 acts via a cytotoxic mechanism that seems to be p53-independent. Regarding the apoptotic mechanism of PTX-2, we postulate that in the case of Hep3B cells, the mechanism probably begins with the activation of the extrinsic pathway by increasing the expression of death receptors such as DR4 and DR5 and caspase- 8 was probably the first element recruited by the extrinsic pathway triggered by the binding of the death ligand to its receptor. Then the downregulation of another apoptosis inhibitor could trigger apoptosis through the mitochondria. More notably, the novel NAG-1 pathway had been proven to be one of the molecular targets that mediate the cytotoxic actions of PTX-2. Egr-1 may be another transcriptional factor that is responsible for the PTX-2-induced apoptotic action, although its correlation with NAG-1 regulation could not be confirmed. The present study explains in part the molecular basis for using PTX-2 as a potential anti-tumorigenic agent in $\mathrm{p} 53$-deficient tumors.

\section{Acknowledgements}

This study was supported by a grant (M2007-11) from the Marine Bioprocess Research Center of the Marine Bio 21 Center funded by the Ministry of Maritime Affairs and Fisheries, Korea.

\section{References}

1. Okada H and Mak TW: Pathways of apoptotic and non-apoptotic death in tumour cells. Nat Rev Cancer 4: 592-603, 2004.

2. Debatin KM: Apoptosis pathways in cancer and cancer therapy. Cancer Immunol Immunother 53: 153-159, 2004.

3. Jin Z and el-Deiry WS: Overview of cell death signaling pathways. Cancer Biol Ther 4: 139-163, 2005.

4. Wesche-Soldato DE, Swan RZ, Chung CS and Ayala A: The apoptotic pathway as a therapeutic target in sepsis. Curr Drug Targets 8: 493-500, 2007.

5. Chowdhury I, Tharakan B and Bhat GK: Current concepts in apoptosis: The physiological suicide program revisited. Cell Mol Biol Lett 11: 506-525, 2006.

6. Fulda S and Debatin KM: Extrinsic versus intrinsic apoptosis pathways in anticancer chemotherapy. Oncogene 25: 4798-4811, 2006.

7. Halaby MJ and Yang DQ: p53 translational control: a new facet of p53 regulation and its implication for tumorigenesis and cancer therapeutics. Gene 395: 1-7, 2007.

8. Coutts AS and La Thangue N: The p53 response during DNA damage: impact of transcriptional cofactors. Biochem Soc Symp 73: 181-189, 2006.

9. Giono LE and Manfredi JJ: The p53 tumor suppressor participates in multiple cell cycle checkpoints. J Cell Physiol 209: 13-20, 2006

10. el-Deiry WS, Tokino T, Velculescu VE, Levy DB, Parsons R, Trent JM, Lin D, Mercer WE, Kinzler KW and Vogelstein B: WAF1, a potential mediator of p53 tumor suppression. Cell 75: $817-825,1993$.

11. Zinkel S, Gross A and Yang E: Bcl-2 family in DNA damage and cell cycle control. Cell Death Differ 13: 1351-1359, 2006.

12. Moll UM, Wolff S, Speidel D and Deppert W: Transcriptionindependent pro-apoptotic functions of p53. Curr Opin Cell Biol 17: 631-636, 2005.

13. Murakami Y, Hayashi K, Hirohashi S and Sekiya T: Aberrations of the tumor suppressor p53 and retinoblastoma genes in human hepatocellular carcinomas. Cancer Res 51: 5520-5525, 1991.

14. Chi TY, Chen GG and Lai PB: Eicosapentaenoic acid induces Fas-mediated apoptosis through a p53-dependent pathway in hepatoma cells. Cancer J 10: 190-200, 2004.

15. Mayer AM and Gustafson KR: Marine pharmacology in 2000: antitumor and cytotoxic compounds. Int J Cancer 105: 291-299, 2003. 
16. Newman DJ and Cragg GM: Marine natural products and related compounds in clinical and advanced preclinical trials. J Nat Prod 67: 1216-1238, 2004.

17. McCarthy PJ, Pitts TP, Gunawardana GP, Kelly-Borges M and Pomponi SA: Antifungal activity of meridine, a natural product from the marine sponge Corticium sp. J Nat Prod 55: 1664-1668, 1992.

18. Randazzo A, Bifulco G, Giannini C, Bucci M, Debitus C, Cirino $\mathrm{G}$ and Gomez-Paloma L: Halipeptins A and B: two novel potent anti-inflammatory cyclic depsipeptides from the Vanuatu marine sponge Haliclona species. J Am Chem Soc 123: 10870-10876, 2001.

19. Kim DK, Lee MY, Lee HS, Lee DS, Lee JR, Lee BJ and Jung JH: Polyacetylenes from a marine sponge Petrosia sp. inhibit DNA replication at the level of initiation. Cancer Lett 85: 95-101, 2002.

20. Jung JH, Sim CJ and Lee CO: Cytotoxic compounds from a two-sponge association. J Nat Prod 58: 1722-1726, 1995.

21. Chae HD, Choi TS, Kim BM, Jung JH, Bang YJ and Shin DY: Oocyte-based screening of cytokinesis inhibitors and identification of pectenotoxin-2 that induces Bim/Bax-mediated apoptosis in p53-deficient tumors. Oncogene 24: 4813-4819, 2005.

22. Bae SK, Bae MH, Ahn MY, Son MJ, Lee YM, Bae MK, Lee OH, Park BC and Kim KW: Egr-1 mediates transcriptional activation of IGF-II gene in response to hypoxia. Cancer Res 59: 5989-5994, 1999.

23. Armstrong JS: Mitochondria: a target for cancer therapy. Br J Pharmacol 147: 239-248, 2006.

24. Baek SJ, Kim KS, Nixon JB, Wilson LC and Eling TE: Cyclooxygenase inhibitors regulate the expression of a TGF- $\beta$ superfamily member that has proapoptotic and antitumorigenic activities. Mol Pharmacol 59: 901-908, 2001.

25. Baek SJ, Horowitz JM and Eling TE: Molecular cloning and characterization of human nonsteroidal anti-inflammatory drugactivated gene promoter. Basal transcription is mediated by Sp1 and Sp3. J Biol Chem 276: 33384-33392, 2001.

26. Jang TJ, Kang HJ, Kim JR and Yang CH: Non-steroidal antiinflammatory drug activated gene (NAG-1) expression is closely related to death receptor-4 and -5 induction, which may explain sulindac sulfide induced gastric cancer cell apoptosis. Carcinogenesis 25: 1853-1858, 2004.
27. Ko JK, Leung WC, Ho WK and Chiu P: Herbal diterpenoids induce growth arrest and apoptosis in colon cancer cells with increased expression of the nonsteroidal anti-inflammatory drug-activated gene. Eur J Pharmacol 559: 1-13, 2007.

28. Eling TE, Baek SJ, Shim M and Lee CH: NSAID activated gene (NAG-1), a modulator of tumorigenesis. J Biochem Mol Biol 39: 649-655, 2006.

29. Martinez JM, Sali T, Okazaki R, Anna C, Hollingshead M, Hose C, Monks A, Walker NJ, Baek SJ and Eling TE: Druginduced expression of nonsteroidal anti-inflammatory drugactivated gene/macrophage inhibitory cytokine-1/prostate-derived factor, a putative tumor suppressor, inhibits tumor growth. J Pharmacol Exp Ther 318: 899-906, 2006.

30. Wilson LC, Baek SJ, Call A and Eling TE: Nonsteroidal antiinflammatory drug-activated gene (NAG-1) is induced by genistein through the expression of p53 in colorectal cancer cells. Int J Cancer 105: 747-753, 2003.

31. Baek SJ, Kim JS, Jackson FR, Eling TE, McEntee MF and Lee SH: Epicatechin gallate-induced expression of NAG-1 is associated with growth inhibition and apoptosis in colon cancer cells. Carcinogenesis 25: 425-2432, 2004.

32. Baek SJ, Kim JS, Nixon JB, DiAugustine RP and Eling TE: Expression of NAG-1, a transforming growth factor- $\beta$ superfamily member, by troglitazone requires the early growth response gene EGR-1. J Biol Chem 279: 6883-6892, 2004.

33. Quinones A, Dobberstein KU and Rainov NG: The egr-1 gene is induced by DNA-damaging agents and non-genotoxic drugs in both normal and neoplastic human cells. Life Sci 72: 2975-2992, 2003.

34. Skerka C, Decker EL and Zipfel PF: Coordinate expression and distinct DNA-binding characteristics of the four EGR-zinc finger proteins in Jurkat T lymphocytes. Immunobiology 198: 179-191, 1997.

35. Santiago FS and Khachigian LM: Ets-1 stimulates plateletderived growth factor A-chain gene transcription and vascular smooth muscle cell growth via cooperative interactions with $\mathrm{Sp} 1$. Circ Res 95: 479-487, 2004.

36. Lim JH, Park JW, Min DS, Chang JS, Lee YH, Park YB, Choi KS and Kwon TK: NAG-1 up-regulation mediated by EGR-1 and p53 is critical for quercetin-induced apoptosis in HCT116 colon carcinoma cells. Apoptosis 12: 411-421, 2007. 